\title{
57. Dense Core Vesicles in the Neuronal Perikarya of the Hypothalamic Arcuate Nucleus of Female Mice
}

\author{
By Masako NishizuKA*) and Seiichiro KAWAshimA**) \\ Zoological Institute, Faculty of Science, University of Tokyo, \\ Bunkyo-ku, Tokyo 113 \\ (Communicated by Kiyoshi Takewaki, M. J. A., June 15, 1978)
}

Dopamine (DA) neurons in the arcuate nucleus (ARC) send their axons to the median eminence (Fuxe and Hökfelt, 1969; Jonsson et al., 1972; Björklund et al., 1973), and regulate the secretion of gonadotropins and prolactin (Fuxe and Hökfelt, 1969; Ahren and Fuxe, 1971; Hökfelt and Fuxe, 1972). Nishizuka (1978a) has indicated that the distribution of DA neuronal perikarya is limited to particular regional areas in the ARC of female mice, neurons with a large amount of DA in the medial area of the middle region of the ARC (mARC), and those with a small amount of DA in the ventromedial area of the mARC (vm-mARC). Moreover, Nishizuka (1978b) has reported that neuronal perikarya containing dense core vesicles (DCVs) distribute predominantly in the vm-mARC of female mice, and estrogen administration during early postnatal life advances the maturation of these neurons. The purpose of the present electronmicroscopical study is to determine whether DA is contained in DCVs by means of pharmacological procedures.

Materials and methods. Female mice (90-100 days of age, 19$21 \mathrm{~g}$ in body weight) of the $\mathrm{C} 3 \mathrm{H} / \mathrm{Tw}$ strain maintained in this laboratory were used as materials. Arcuate nuclei were obtained from 4 intact mice at diestrus, 4 mice given $10 \mathrm{mg}$ nialamide (Sigma) plus $1 \mathrm{mg}$ $\alpha$-methyl-dopa (Sigma), and 4 mice given $200 \mu \mathrm{g}$ reserpine (Serpasil, Ciba). Procedures of administration of the drugs were exactly the same as those described in the previous paper (Nishizuka, 1978a). Sacrifice of animals, preparation of the mARC for electron microscopy, studies of the location of neurons containing DCVs, and estimation of the number of DCVs in each neuron were carried out as described in the previous report (Nishizuka, 1978b). The distribution patterns of DCVs were compared by Kolmogorov-Smirnov's twosample test among the 3 groups of mice. The significance of differences

\footnotetext{
*) Present address: Department of Anatomy, Juntendo University School of Medicine, Bunkyo-ku, Tokyo 113.

**) Send offprint requests to Dr. S. Kawashima.
} 
between mean numbers of DCVs was determined using Student's t-test.

Results. In both intact mice and those given reserpine or nialamide plus $\alpha$-methyl-dopa, neurons containing DCVs were present in
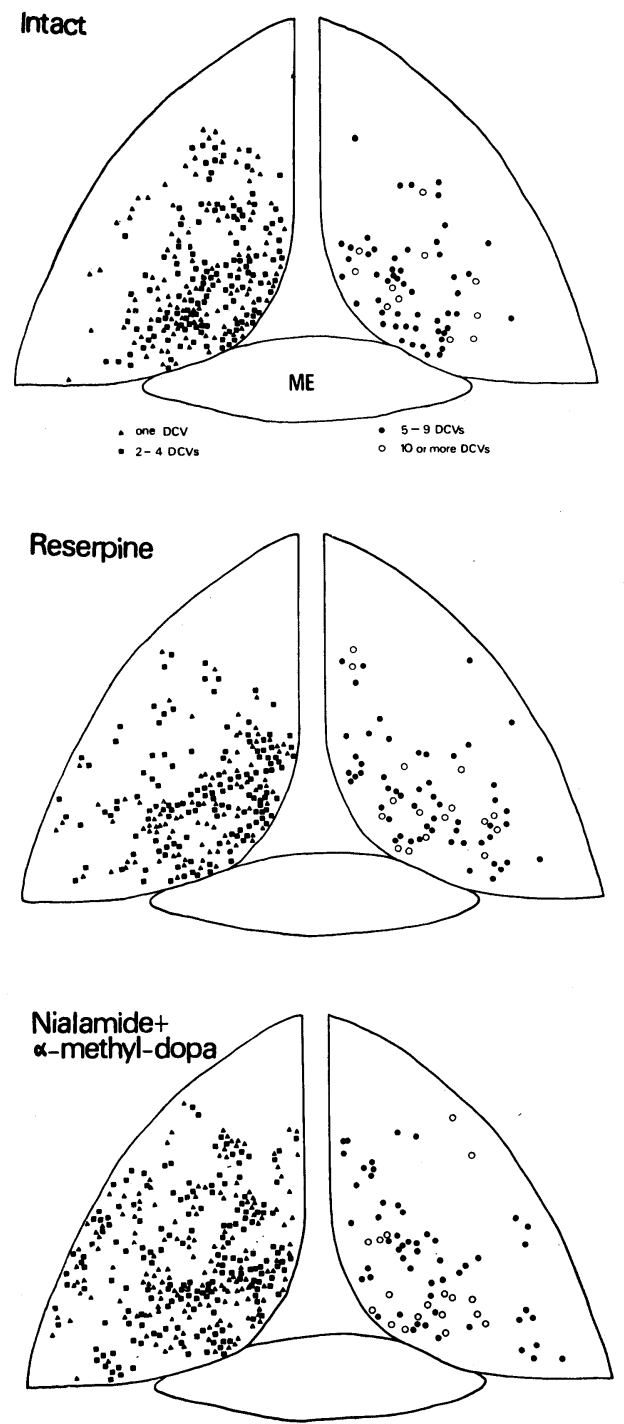

Fig. 1. Distribution of neurons containing DCVs in the mARC of intact mice (top), mice given reserpine (middle), and mice given nialamide plus $\alpha$-methyl-dopa (bottom). The loci of neurons in right and left halves of the mARC are based on observations in 4 specimens. Left halves of the figures show the neurons containing one (triangle) and 2-4 DCVs (square), right halves the neurons with 5-9 (solid circle) and 10 or more DCVs (open circle). ME, median eminence. 
the mARC (Fig. 1). Neurons containing 1-4 DCVs per ultrathin section distributed all over the $\mathrm{mARC}$. However, neurons containing more than 5 DCVs were predominant in the vm-mARC in all groups of mice.

About $35 \%$ of neurons of the mARC contained 1-4 DCVs per ultrathin section (Fig. 2). The mean number of the DCVs was 1.7 in the intact mice, 2.0 in those given reserpine, and 1.8 in the animals treated with nialamide plus $\alpha$-methyl-dopa. Thus, the mean values for these 3 groups of mice were not significantly different from each other (Student's t-test). About $10 \%$ of neurons per section of the mARC contained more than $5 \mathrm{DCVs}$, the mean number of DCVs being 8.6 in the intact mice, 7.9 in the mice given reserpine, and 7.7 in those given nialamide plus $\alpha$-methyl-dopa. Again, the 3 groups of mice exhibited no significant differences in the mean values. The distribution pattern of the numbers of DCVs did not differ among the 3 groups. (Kolmogorov-Smirnov's test).

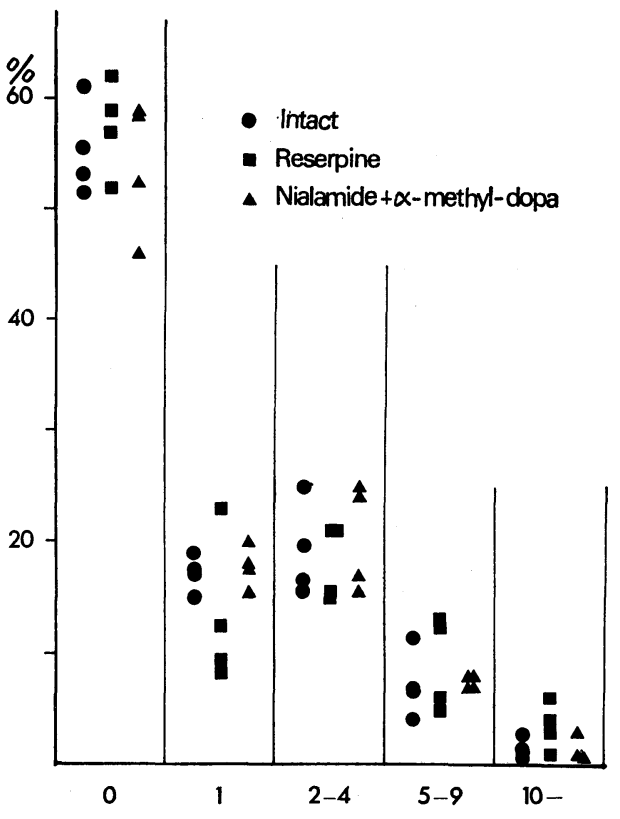

No. of DCVs in neurons of $m$ ARC

Fig. 2. Numbers of DCVs in neuronal perikarya of the mARC of intact mice, mice given reserpine, and mice given nialamide plus $\alpha$ methyl-dopa. Each point depicts the percent of the number of neuronal perikarya containing DCVs in each neuron, $0,1,2-4,5-9$ and more than 10.

Discussion. Nishizuka (1978a) has shown that treatment with reserpine brought about total extinction of fluorescence in DA 
neurons in the ARC of female mice, whereas treatment with nialamide plus $\alpha$-methyl-dopa augmented the fluorescence in DA neurons making identification of neurons containing a small amount of DA easier. However, in the present study neither of the two types of treatments exerted any significant influence on the frequency and distribution of neurons containing DCVs in the mARC.

Ibata et al. (1974) suggested that DA might be contained in DCVs in the $\mathrm{ARC}$, on the basis of the finding that, following intraventricular injection of a large amount of 5-hydroxy-DA, its uptake took place in granules and lysosomes in neuronal perikarya of the cat ARC, although the uptake failed to occur after injection of a small amount (Ibata et al., 1975). If this holds for the mouse, the present findings may possibly be explained by assuming that there is a DA-carrier resistant to reserpine treatment in DCVs and that, although $\alpha$-methylDA is not accumulated in DCVs, endogeneous DA is stored in DCVs in DA neurons. Nevertheless, it is more probable that DA is not an important constituent of DCVs in the mARC, since the distribution pattern of DA neurons was different from that of neurons bearing many DCVs (Nishizuka, 1978a, b). Neurons with many DCVs occurred in the vm-mARC where neurons containing but a small amount of DA were present. Furthermore, in the area of the mARC with a number of neurons containing a large amount of DA rarely exhibited neurons bearing many DCVs. Accordingly, DCVs in the vm-mARC appear to contain some substance other than DA for the major constituent.

Summary. Dense core vesicles (DCVs) in neuronal perikarya in the arcuate neurons of female adult mice were counted on ultrathin sections. In the ventromedial area of the middle region of the ARC (vm-mARC), a large number of neurons contained varying numbers of DCVs. Treatments of mice with reserpine or nialamide plus $\alpha$ methyl-dopa brought about no significant change in the occurrence and distribution of neurons with DCVs. Therefore, it is unlikely that DA is concentrated into DCVs in the vm-mARC.

Acknowledgements. The authors wish to express their cordial thanks to Professor Emeritus K. Takewaki, M. J. A., and Professor K. Ueda of the University of Tokyo for their criticism and kind help in preparing the manuscript. This study was partly supported by a Grant-in-Aid for Scientific Research from the Ministry of Education of Japan.

\section{References}

Ahren, K., Fuxe, K., Hamberger, L., and Hökfelt, T. (1971): Turnover changes in the tubero-infundibular dopamine neurons during the ovarian cycle of the 
rat. Endocrinology, 88, 1415-1424.

Björklund, A., Moore, R. Y., Nobin, A., and Stenevi, U. (1973) : The organization of tubero-hypophyseal and reticulo-infundibular catecholamine neuron systems in the rat brain. Brain Res., 51, 171-191.

Fuxe, K., and Hökfelt, T. (1969): Catecholamines in the hypothalamus. Frontiers in Neuroendocrinology (W. F. Ganong and L. Martini eds.), Oxford Univ. Press, New York, pp. 47-96.

Hökfelt, T., and Fuxe, K. (1972) : Effects of prolactin and ergot alkaloids on the tubero-infundibular dopamine (DA) neurons. Neuroendocrinology, 9, 100-122.

Ibata, Y., Nojyo, Y., Matsuura, T., and Sano, Y. (1974) : Effect of high dosage of 5-hydroxy-dopamine on the arcuate nucleus of the cat and its possible uptake by the catecholamine-containing neuronal soma. J. Electron Microscopy, 23, 295-299.

Ibata, Y., Nojyo, Y., Matsuura, T., Yoshikawa, H., and Sano, Y. (1975) : Electron microscopy of the arcuate nucleus of normal and 5-hydroxy-dopamine treated cats. Cell Tiss. Res., 160, 139-153.

Jonsson, G., Fuxe, K., and Hökfelt, T. (1972) : On the catecholamine innervation of the hypothalamus, with special reference to the median eminence. Brain Res., 40, 271-281.

Nishizuka, M. (1978a) : Topography of the neurons responding to estrogen in the hypothalamic arcuate nucleus of immature female mice. Brain Res. (in press).

(1978b): Topography of the dopamine neurons in the arcuate nucleus of the mouse hypothalamus. Acta Anatomica (in press). 